Cuadernos de la

Cátedra CaixaBank de

Responsabilidad Social

Corporativa

№ 36

Octubre de 2017

DOI: https://dx.doi.org/10.15581/018.ST-455

||l|: | de Responsabilidad Social Corporativa

\section{Activismo accionarial desde la perspectiva de la responsabilidad social corporativa}

\section{Marta Remacha}

Cátedra CaixaBank de

Responsabilidad Social Corporativa 


\section{ÍNDICE}

1. INTRODUCCIÓN

2. DEFINICIÓN Y CONTEXTO 4

3. RADIOGRAFÍA DEL ACTIVISMO ACCIONARIAL 6

$\begin{array}{lc}\text { 3.1. ACTORES } & 6\end{array}$

$\begin{array}{lr}\text { 3.2. OBJETIVOS } & 10\end{array}$

$\begin{array}{lr}\text { 3.3. INSTRUMENTOS } & 12\end{array}$

4. RECOMENDACIONES PARA EL DIÁLOGO CON ACCIONISTAS 16

$\begin{array}{lr}\text { 4.1. ANTICIPARSE } & 16\end{array}$

$\begin{array}{ll}\text { 4.2. PLANIFICAR } & 16\end{array}$

4.3. MANTENER RELACIONES CONTINUADAS 17

$\begin{array}{ll}\text { 4.4. DAR RESPUESTA } & 17\end{array}$

$\begin{array}{ll}\text { 4.5. REALIZAR UN SEGUIMIENTO } & 17\end{array}$

5. INFLUENCIA DEL ACTIVISMO ACCIONARIAL EN LA RESPONSABILIDAD SOCIAL CORPORATIVA 18

6. CONCLUSIONES: RESPONSABILIDAD SOCIAL CORPORATIVA Y CREACIÓN DE VALOR 20

7. BIBLIOGRAFÍA 21 
En las últimas décadas

la intervención de

los accionistas en la

administración de la

empresa ha resurgido

bajo la forma del

"activismo accionarial».
Esta forma de

activismo se basa

en el uso del poder

accionarial para influir

en el comportamiento

corporativo.

\section{INTRODUCCIÓN}

Entre las empresas cotizadas, los accionistas son uno de los grupos de interés más importantes: como propietarios de las acciones, dotan a la compañía del capital necesario para que pueda realizar su actividad; como contrapartida, reciben una serie de derechos económicos (como participar en los beneficios de la empresa) y políticos (acudir a las juntas generales de accionistas [JGA] y expresar su opinión y votar en las mismas) con los que influir sobre la marcha de la entidad.

Los derechos políticos ofrecen a los accionistas (propietarios) un mecanismo de control con el que asegurar que los intereses de los directores y consejeros (administradores) se mantengan alineados con los suyos. Sin embargo, es frecuente que estos derechos no se ejerzan, ya que si precisamente la propiedad (accionistas) y la administración (directivos y consejeros) de la empresa se encuentran separadas es por las facilidades que ofrece al accionista esta delegación de poderes, de tal manera que puede obtener rentabilidad de su inversión sin asumir los costes de la administración directa de la compañia.

En las últimas décadas, sin embargo, la intervención de los accionistas en la administración de la empresa y el ejercicio de los derechos a presentar propuestas y a votar en las juntas generales ha resurgido, como parte de un movimiento financiero y social que se denomina "activismo accionarial». Bajo este movimiento se agrupan los accionistas que deciden utilizar su capacidad de influencia para introducir cambios en la gobernanza, la estrategia, las políticas y las prácticas de la entidad. En muchos casos, esta intervención se alinea con los principios de maximización del valor económico, impulsando cambios operativos que buscan la rentabilidad a corto plazo; pero en muchos otros, está suponiendo un incentivo para la mejora del gobierno corporativo y la responsabilidad social corporativa (RSC). Este último tipo de mejoras están siendo auspiciadas por inversores socialmente responsables, que ven en el buen gobierno y la sostenibilidad mecanismos para garantizar sus derechos, el comportamiento justo de la empresa con la sociedad y, en última instancia, la creación de valor a largo plazo.

A la vista de la importancia creciente de este movimiento y de su capacidad para impulsar la RSC de las empresas, el Cuaderno 36 de la Cátedra CaixaBank se ocupa de explicar qué es el activismo accionarial, quiénes son sus actores, qué persiguen y cuáles son sus medios de actuación, así como de qué manera está afectando a la empresa y cómo puede preparase esta para dialogar y dar respuesta a sus demandas.

\section{DEFINICIÓN Y CONTEXTO}

Los accionistas, como propietarios de títulos de una sociedad cotizada, poseen una serie de derechos políticos por los cuales pueden acudir, expresar su opinión y votar en las JGA; además, tienen representación en el Consejo de Administración a través de los consejeros dominicales ${ }^{1}$ y pueden, en la mayoría de las ocasiones, mantener una estrecha relación con la compañía y sus directivos. Esto les confiere una capacidad de influencia sobre la empresa en la que se fundamente el activismo accionarial, definido como «el uso del poder accionarial para influir en el comportamiento corporativo, a través de la interacción directa con la empresa (por ejemplo, comunicación con el equipo directivo o la junta), el envío o apoyo de propuestas o el seguimiento de las recomendaciones de asesores de voton (Global Sustainable Investment Alliance, 2017).

El activismo empresarial no es un fenómeno nuevo: cualquier forma de diálogo, petición, cuestionamiento o queja hacia la compañia pueden considerarse formas tempranas de este tipo de movimiento accionarial. La emergencia del activismo como movimiento organizado entendiendo por 'organizado' el momento en el que los inversores lo emplean como parte de una estrategia de inversión (0'Rourke, 2003)- puede remontarse a la década de los ochenta, en Estados Unidos - una deal decade que se caracterizó por la intensificación de las absorciones que, a ojos de los accionistas, devaluaban las acciones-. Esto motivó la aparición de una primera generación de activismo, organizado para bloquear este tipo de operaciones y para evitar determinadas

${ }^{1}$ Consejeros dominicales: son los consejeros que forman parte del Consejo de Administración por su condición de accionistas de la sociedad o bien por detentar una participación superior al 5\% del capital. Pueden formar parte del Consejo de forma directa 0 a través de un representante. 
prácticas contrarias al buen gobierno como los contratos blindados, el greenmailing (comprar un número suficiente de acciones como para amenazar con una toma de control, forzando al resto de propietarios de la compañía a recomprar estas acciones a un precio prémium) o las píldoras envenenadas (operaciones defensivas por parte de empresas amenazadas por una OPA [oferta pública de acciones] hostil).

El activismo fue evolucionando en los años noventa para centrarse en acciones de presión hacia cuestiones específicas de gobierno corporativo (separación de las figuras del primer ejecutivo y el presidente, incorporación de consejeros independientes, composición de los comités de auditoria y retribución) y, progresivamente, fueron introduciendo peticiones sobre asuntos no financieros como vía para mejorar el desempeño corporativo y para no exponerse a las consecuencias negativas de una mala praxis.

En la última década, el activismo accionarial ha continuado creciendo, en esta ocasión, de la mano de fondos de inversión (hedge funds) cuya estrategia es adquirir acciones de compañias cotizadas e influir en su estrategia (y aumentar su desempeño financiero y, por consiguiente, su valor) a través del activismo. Estos fondos han demostrado tener unas rentabilidades superiores a otros tipos de fondos de inversión, lo que ha atraído la atención de numerosos accionistas y ha animado a más inversores a seguir esta estrategia (CMS, 2016). Este tipo de activismo configura una primera vertiente del activismo accionarial, que podría denominarse "financiero", orientado a la rentabilidad de la inversión. A este habría que sumar otro tipo de activismo, de tipo más "social», que se enmarca dentro del contexto más amplio de la inversión socialmente responsable (ISR) (Goranova y Verstegen, 2014; Uysal y Tsetsura, 2015).

La ISR es una tendencia que combina criterios sociales, ambientales y de gobierno corporativo (ESG, por sus siglas en inglés) con los criterios tradicionalmente financieros para realizar una inversión. Los inversores socialmente responsables pueden seguir diferentes estrategias, como no invertir en empresas de determinados sectores (por ejemplo, armamentístico), invertir en compañias que cumplen con unos estándares internacionales definidos, invertir en temas o activos específicamente relacionados con la sostenibilidad (por ejemplo, energías limpias, tecnologías verdes o agricultura sostenible) o realizar inversiones dirigidas a solucionar problemas sociales 0 medioambientales específicos. Entre estas estrategias encontraríamos también la participación empresarial y el activismo accionarial (corporate engagement and shareholder action) (Global Sustainable Investment Alliance, 2017).

La ISR, y dentro de esta, el activismo accionarial social, es una tendencia que se ha consolidado en los últimos años ${ }^{2}$ debido, en primer lugar, a la constatación por parte de los inversores de que existe una correlación positiva entre el desempeño financiero y el desempeño ESG. Así mismo, determinados escándalos financieros posibilitados por falta de transparencia, responsabilidad y buen gobierno en las empresas han hecho de este tipo de criterios un medio muy eficaz para valorar la calidad de los activos en los que invertir. Finalmente, los acuerdos y cambios regulatorios promovidos desde los gobiernos y la Administración Pública, junto con la mayor conciencia social y medioambiental tanto de inversores como de la sociedad civil, la constatación de que las inversiones son igualmente rentables o el incremento del escrutinio y la atención pública hacia estos asuntos también han incentivado este crecimiento de la inclusión de criterios ESG en las decisiones de inversión (World Resource Institute, 2016).

De este modo, el activismo accionarial se ha convertido en una práctica al servicio de los intereses de los accionistas e inversores, lo que se traduce, en muchas ocasiones, en el avance de prácticas de gobierno corporativo, RSC o sostenibilidad, que crean valor para el accionista y el resto de grupo de interés ("activismo social»); mientras que, en otras tantas, se dirige exclusivamente a la mejora del desempeño financiero como vía para maximización el valor para el accionista ("activismo financiero»). Como consecuencia, el campo del activismo accionarial es un crisol de actores, objetivos e instrumentos que es necesario que la empresa conozca para poder dar una respuesta adecuada.

\author{
El activismo introduce \\ peticiones sobre asuntos \\ no financieros como \\ vía para mejorar el \\ desempeño corporativo y \\ para no exponerse a las \\ consecuencias negativas \\ de una mala praxis.
}


La introducción

de prácticas más

responsables es la mejor

manera de anticipar y

responder al activismo

accionarial.
El terreno de la participación empresarial está poblado por un heterogéneo abanico de activistas que incluye, entre otros, accionistas minoritarios, inversores institucionales, fondos de inversión responsable, sindicatos o fondos de alto riesgo.
En las páginas que siguen veremos cómo el activismo accionarial está impulsando prácticas más responsables a nivel corporativo y mostraremos cómo la introducción de este tipo de prácticas es la mejor manera de anticipar y responder al activismo. Tanto si el fin que persiguen los activistas es el de la sostenibilidad de la compañía como si no, el gobierno corporativo y la RSC redundan en la protección de los derechos de los accionistas, el aumento de la transparencia o la mejora del diálogo y las relaciones con los mismos.

\section{RADIOGRAFÍA DEL ACTIVISMO ACCIONARIAL}

La existencia de distintas tendencias dentro del activismo, una más financiera y otra más social, conlleva que en el universo del activismo accionarial convivan diferentes actores con diversas preocupaciones, desde inversores institucionales y fondos de cobertura enfocados a aumentar la rentabilidad, dirigiendo sus campañas hacia asuntos de gobierno corporativo como pueden ser la compensación de directivos, la composición del Consejo de Administración o la salvaguarda de los derechos de los accionistas, hasta accionistas minoritarios o fondos de inversión responsable que se preocupan por un desempeño económico, social y ambiental sostenible (Goranova y Verstegen, 2014).

Además de los objetivos perseguidos, los instrumentos que unos y otros grupos emplean dependen, en gran medida, de su capacidad de influencia, determinada por diversos factores que van desde el peso de su participación en la compañía (con lo que, por ejemplo, tener acceso directo al primer ejecutivo) hasta su capacidad de movilizar a la sociedad (recurriendo a propuestas o campañas públicas como método para ejercer presión).

Con el fin de entender el escenario del activismo accionarial, exploraremos a continuación quiénes son sus actores y qué motivaciones les guian para seguir una u otra estrategias, o conjugar varias de ellas.

\subsection{ACTORES}

El terreno de la participación empresarial está poblado por un heterogéneo abanico de activistas que incluye, entre otros, accionistas minoritarios, inversores institucionales, fondos de inversión responsable, entidades no lucrativas, sindicatos, fondos de pensiones públicos y privados 0 fondos de alto riesgo. Además de los propios accionistas, diversas figuras han crecido al alero del activismo accionarial, como los asesores de voto (proxy advisors), los proxy solicitors o las agencias de calificación no financiera, capaces de mediar entre compañía y accionistas, y guiar en un sentido $u$ otro la inversión y el activismo.

\subsubsection{Accionistas minoritarios}

Se entiende por accionista minoritario al accionista o grupo sindicado de accionistas que posee menos del 50\% de los títulos de una empresa, de su capital social y su derecho a voto; o que no dispone del mayor paquete de acciones de la sociedad en la que han invertido. En la medida en que las votaciones de la junta se rigen por el principio de mayoría simple, los intereses de estos accionistas minoritarios pueden quedar desprotegidos en favor de quienes tienen la mayoría. Por este motivo, son uno de los colectivos que más sirve del activismo accionarial como mecanismo para hacer valer sus derechos en la compañía.

En España, por ejemplo, contar con el 3\% del capital social da derecho a presentar una propuesta de acuerdo ante la JGA (Jefatura de Estado, 2014). Aunque la propuesta no llegue a ser aprobada, la sola "amenaza» de presentarla puede ser motivo suficiente para que los gestores de la compañía opten por dialogar con los activistas y evitar que la petición llegue a hacerse pública. Así mismo, en compañias donde existe una participación muy repartida, este colectivo puede configurarse como minorías de bloqueo o como minorías bisagra con el objetivo de conseguir una alternancia entre grupos de control. 


\section{JOHN CHEVEDDEN}

Calificado como "el mayor impulsor de propuestas de acuerdo nunca existido", John Chevedden es uno de los accionistas minoritarios activistas más influyentes de Estados Unidos. Cada año presenta numerosas propuestas ante las mayores compañias del pais, centradas en cláusulas muy concretas de gobierno corporativo, con las que pretende aumentar la participación de los accionistas y la rendición de cuentas de los ejecutivos como mecanismo para mejorar las operaciones e incrementar el valor para los accionistas. Algunas de las propuestas que ha presentado han sido:

- Whole Foods Market: cambiar los estatutos para permitir que los accionistas realicen nominaciones de miembros al Consejo.

- Edison International: aumentar de 20 a 50 el número de accionistas que pueden sumar sus acciones para conseguir el 3\% mínimo requerido para proponer candidatos alternativos a las elecciones del Consejo.

- Bank of America: modificar la política de remuneración del primer ejecutivo para que, una vez se retire del cargo, no pueda vender sus acciones hasta que haya trascurrido un año.

- Alphabet y Ford: cambiar la estructura del accionariado de manera que cada acción equivalga a un voto.

- Tesla: someter anualmente a reelección a los miembros del Consejo de Administración.

Fuente: Kerber, R. (2013), "Special Report: Economy-class activist investor crashes the corporate party", Reuters, 23 de octubre de 2013. Fecha de último acceso: septiembre de 2017.

\subsubsection{Inversores institucionales}

Bajo este término genérico se designa a las organizaciones que invierten grandes cantidades de dinero (propio o ajeno) en títulos y fondos: bancos, fondos de pensiones, compañias de seguros, sociedades de inversión, etc. Se basan en la captación de los ahorros de un gran número de inversores (particulares, empresas y otras entidades) para invertirlos, total o parcialmente, en una cesta de distintos activos financieros como acciones, renta fija pública y privada o productos derivados y estructurados.

La mayoría de las instituciones de inversión colectiva participan en el capital social de numerosas empresas, por lo que carecen de incentivos para conocer a fondo todos los sectores y proponer cambios de gestión en las sociedades en las que intervienen. Su objetivo es obtener unos rendimientos en línea con los del mercado, de forma que, si una empresa de la cartera del inversor institucional no se comporta conforme a lo esperado, el inversor probablemente optará por vender su participación (lo que se conoce como exit o vote with their feet) y compensar las pérdidas con ganancias en otras compañias (Goodman et al., 2014).

En lo que atañe a activismo accionarial, este colectivo suele preocuparse por cuestiones de gobierno corporativo (eliminación de medidas anti-OPA, control de la remuneración de los ejecutivos, elección de los consejeros independientes, control de las transacciones vinculadas...), sobre las que cuenta con expertise suficiente 0 , en su defecto, contratan a consultores externos especializados para que les asesoren (proxy advisors) (Puente González, 2017). No suelen entrar en la gestión de las empresas participadas ni proponer cambios a nivel de las políticas o estrategia corporativas, si bien sí que pueden llegar a intervenir en aquellas situaciones en las que poseen un gran número de acciones que harian cara o difícil la desinversión (Goodman et al., 2014).

Mención aparte merecen los fondos de inversión y de pensiones socialmente responsables, cuya finalidad no es únicamente la obtención de rentabilidad, sino que, además, pretenden dirigir el ahorro hacia empresas u organizaciones de acuerdo con el ideario de la institución. Parte de ellos emplea el activismo accionarial como estrategia de ISR, destacando los fondos de pensiones públicos, los fondos de pensiones de empleo o los planes de previsión social empresarial, puesto que la creación de valor a largo plazo inherente a su visión les lleva a impulsar con especial mimo las variables sociales y ambientales que aseguren la sostenibilidad de la compañía (Sjöström, 2008). 
Los fondos de cobertura representan una de las formas de activismo accionarial más potentes, además de polémicas.

\section{La finalidad principal} de las actuaciones de ONGs y sindicatos es dar visibilidad al tema objeto de la campaña y concienciar a otros inversores con mayor capacidad de influencia.

\subsubsection{Fondos de cobertura (hedge funds)}

También denominados «instrumentos de inversión alternativa" o "fondos de alto riesgo", se trata de sociedades privadas de inversión que manejan títulos de terceros para cubrirlos ante posibles riesgos y/o incrementar su valor. Se caracterizan por estar dirigidos a la obtención de la máxima rentabilidad y, en lo que respecta al activismo accionarial, acostumbran a identificar compañias saneadas pero que podrian ser más rentables y a adquirir un porcentaje significativo de las acciones (que les permite hacerse con control o influir en el Consejo), a partir de lo cual introducen cambios en la estrategia corporativa (PwC, 2015).

En España, la CNMV (Comisión Nacional del Mercado de Valores) únicamente permite comercializar aquellos hedge funds de paises terceros países con los que haya firmado un memorando de entendimiento, lo que limita considerablemente el número de fondos de cobertura que pueden tener inversores institucionales españoles. No obstante, son un tipo de institución muy presente en las inversiones de EE. UU. y representan una de las formas de activismo accionarial más potentes, además de polémicas (Goranova y Verstegen, 2014). Así, se trata de un activismo accionarial de carácter estratégico y dirigido a aumentar el valor de la compañia, reforzando el control sobre los directivos y reduciendo los problemas de agencia; si bien, por otra parte, las estrategias de inversión empleadas por estos fondos, orientadas a maximizar la rentabilidad, pueden incurrir en el cortoplacismo, la especulación o el uso de prácticas impropias del buen gobierno corporativo (Puente González, 2017).

\subsubsection{Organizaciones no gubernamanentales y sindicatos}

Históricamente vinculados al activismo y al empuje de prácticas más justas a nivel comercial, laboral, social, ambiental o ético en las empresas, la implicación en el activismo accionarial de las organizaciones no gubernamentales (ONG) y los sindicatos va desde la influencia sobre accionistas e inversores, a través de la participación en grupos de trabajo o el estímulo de campañas públicas de sensibilización o presión, hasta la adquisición o petición de cesión de acciones (como mecanismo para interceder directamente en la junta general), además de los propios comunicados peticiones que puedan enviar a los directivos.

En ocasiones, estas entidades logran implementar cambios en la estrategia de las compañias; sin embargo, es más frecuente que no tengan peso suficiente para hacer prosperar sus peticiones. Por este motivo, la finalidad principal de sus actuaciones es dar visibilidad al tema objeto de la campaña y concienciar (o presionar) a otros inversores que sí tienen capacidad de influencia.

A estas organizaciones se les atribuye, además, una contribución histórica al avance del activismo institucional, al haber facilitado, a nivel legal y organizacional, la presentación de propuestas, la introducción de cambios en el comportamiento corporativo o la oposición a las propuestas de los gestores (Sjöström, 2008). 
ACTIVISMO ACCIONARIAL CONTRA LA EXPERIMENTACIÓN ANIMAL

La organización por los derechos de los animales PETA (People for the Ethical Treatment of Animals [Personas por el Trato Ético de los Animales]) practica, desde 1987, el activismo accionarial. Más de ochenta entidades han sido objetivo de sus campañas, entre las que se encuentran 3M, Dow, DuPont, Johnson \& Johnson, Hermes, LVMH, Prada o Procter \& Gamble. Las campañas se dirigen a poner fin a la experimentación con animales, así como a la implementación de mejores prácticas (realización de los test sin animales, aumento y colaboración en la investigación científica sobre métodos de experimentación alternativos, ampliación de los programas toxicológicos, sustitución de materiales de origen animal por sintéticos, impulso de la formación interna, etc.

PETA se sirve de la adquisición o el donativo de acciones para participar en la junta general de estas compañias, presentando propuestas de acuerdo para abolir esta práctica, u obteniendo apoyos suficientes para reunirse y trabajar juntamente con la junta directiva en esta dirección. Para dar visibilidad a sus peticiones y ejercer presión, es frecuente que recurran también a la cobertura mediática.

Esta adquisición de acciones no va asociada a la búsqueda de una rentabilidad económica: así, en 2013 PETA invirtió en acciones del parque de atracciones SeaWorld de Orlando, para liberar a los animales en cautividad. Tras la OPA de PETA, el precio de las acciones se devaluó en un $50 \%$.

Fuente: PETA, "Shareholders campaings». Fecha de último acceso: septiembre de 2017.

\subsubsection{Asesores de voto (proxy advisors)}

Los proxy advisors o asesores de voto son empresas que ofrecen sus servicios de asesoramiento a inversores institucionales emitiendo recomendaciones, a favor o en contra, sobre distintos aspectos en materia de gobierno corporativo, además de otras cuestiones, que serán objeto de discusión en el orden del día de la JGA (PwC, 2013). Son una figura con especial presencia en Estados Unidos, donde existe obligatoriedad de voto para los inversores institucionales. Debido a la amplitud de la cartera que manejan gran parte de estos inversores y, por consiguiente, la alta complejidad y variedad de temas que tienen que analizar para cada JGA, muchos recurren al soporte de estos asesores para decidir el sentido de su voto en cada acuerdo a tomar. En este sentido, los proxy advisors forman también parte de la sociología del activismo accionarial, por su capacidad para apoyar las propuestas de cambio presentadas por otros inversores, o, si el voto es negativo, para evitar que prosperen.

\subsubsection{Proxy solicitors}

Los proxy solicitorsson entidades contratadas por las compañías cotizadas con una doble finalidad: facilitar al Consejo de Administración la identificación y el conocimiento de los accionistas, y desarrollar y mantener mecanismos de diálogo con los inversores institucionales. Esta labor es imprescindible para que el Consejo puede desplegar estrategias adecuadas para mitigar el impacto, por ejemplo, de una campaña activista y alinear los intereses de los accionistas con el Consejo de Administración. Así, los proxy solicitors aportan conocimiento sobre los accionistas que, en conjunción con la práctica del diálogo, permite presentar o convenir propuestas más acordes con los intereses de los accionistas y mantener unos niveles altos de confianza en la dirección y el Consejo (PwC, 2013).

\subsubsection{Agencias de calificación no financiera}

De manera similar a las agencias de calificación, estas entidades se dedican a emitir una opinión sobre el desempeño de las empresas, pero, en lugar de centrarse en su calidad y solvencia crediticia, analizan criterios de tipo ambiental y social. Con esta información, los inversores pueden hacerse una idea del valor intangible de la organización y dirigir su inversión.

Aunque hay numerosas agencias de calificación no financiera en el mundo, el mercado está controlado por unas pocas (Vigeo, Innovest, Oekom, SIRI Company) que suelen servirse de los indices socialmente responsables para guiar la inversión. La inclusión (o exclusión) de las acciones en estos índices es indicativa de la valoración que estas agencias realizan del desempeño ESG de la compañia y, por tanto, son un criterio que utilizan principalmente las instituciones de inversión colectiva para conformar sus carteras (Fernández Izquierdo, 2011). 
Los hedge funds

tienden a introducir

cambios en la estrategia

corporativa, la gestión,

la asignación del capital

o las operaciones con

vistas a mejorar el

desempeño financiero de

la compañía.
Tanto las agencias como los índices actúan como intermediarios en el panorama de la inversión, ofreciendo a las compañias la oportunidad de complementar la información financiera dada a sus accionistas mediante una explicación y valoración de su política de gestión de riesgos/ oportunidades y cómo contribuye a su desempeño (Puente González, 2017).

\subsection{OBJETIVOS}

Los objetivos del activismo accionarial son dispares, con base en la heterogeneidad de intereses entre actores, abarcando el amplio espectro que va desde la maximización del valor para el accionista hasta la maximización del valor para la sociedad, pasando por cambios en la estrategia, las prácticas o el gobierno de la compañia para asegurar su adecuado desempeño.

\subsubsection{Cambios en la estrategia}

Este objetivo se dirige a introducir cambios en la estrategia corporativa, la gestión, la asignación del capital, las operaciones, etc. con vistas a mejorar el desempeño. Los hedge funds son los principales inspiradores de este tipo de cambios, ya que, tal como señalábamos anteriormente, su estrategia de inversión se basa en adquirir participaciones en empresas saneadas pero cuyo desempeño financiero es mejorable, precisamente, cambiando de estrategia. Este tipo de campañas son de mayor complejidad, exigiendo un gran expertise para recomendar cambios en la estrategia y tiempo para que dichos cambios arrojen resultados y la inversión se pueda capitalizar.

\section{EL CASO DE CANADIAN PACIFIC RAILWAY}

En el período de 2011 a 2016, la compañia ferroviaria canadiense Canadian Pacific Railway fue objeto de una campaña de activismo accionarial por parte del fondo de cobertura Pershing Square Capital Management, fundado y dirigido por William A. Ackman.

Este fondo adquirió en 2011 acciones en la compañia hasta convertirse en el principal accionista (14,2\%). En 2012, emprendió una campaña contra el Consejo y la dirección de Canadian Pacific, señalando su mala gestión y proponiendo una estrategia para mejorar el desempeño y aumentar el retorno para los accionistas. La campaña se saldó con la dimisión, ese mismo año, del CEO, Fred Green, y otros directivos, incluido el presidente del Consejo, John Cleghorn. Los candidatos nominados por Ackman, entre los que figuraba él mismo como miembro del Consejo, fueron elegidos en la junta general celebrada a continuación. A partir de ese momento, la compañía introdujo cambios en las operaciones, cambió la cultura corporativa y redujo la plantilla, aumentando el retorno anual para los accionistas. En agosto de 2016, Pershing Square vendió sus acciones y en septiembre Ackman dimitió, extrayendo de la acción un beneficio estimado de 2.600 millones de dólares.

Fuente: Y. Allaire y F. Dauphin (2016), "A "Successful" Case of Activism at the Canadian Pacific Railway: Lessons in Corporate Governance», Harvard Law School Forum on Corporate Governance and Financial Regulation [December 23]. Fecha de último acceso: septiembre de 2017.

\subsubsection{Propiciar o evitar una unión o adquisición (M\&A)}

También practicada con mayor frecuencia por los hedge funds, en esta ocasión los activistas intervienen en la compañía para luego ponerla en venta o dividirla a un precio mayor, u oponerse a una transacción para solicitar al comprador un pago mayor por las acciones. Se trata, por tanto, de un mecanismo para aumentar sus beneficios a corto plazo.

\subsubsection{Gestión de las cuentas anuales}

El objetivo en estos casos es movilizar el saldo de caja de la compañía y, normalmente, que se devuelva a los accionistas a través de la reventa de acciones o dividendos.

\subsubsection{Reforma del gobierno corporativo}

Se dirige a introducir mejores prácticas que protejan a los accionistas frente a posibles abusos de los ejecutivos o prácticas especulativas del mercado: blindajes en los contratos, píldoras envenenadas, fallos en los sistemas de control interno, planes de sucesión inadecuados, fallos injustificados en el cumplimiento de códigos de gobierno corporativo, niveles de remuneración inapropiados, etc. 
Las propuestas se dirigen, por ejemplo, a introducir un código de conducta, cambiar el sistema y la periodicidad de elección de los miembros del Consejo, impedir que los consejeros independientes ostenten cargos ejecutivos en otra compañía, aumentar la presencia de consejeros independientes o la diversidad de los miembros del Consejo, limitar el número de años que un consejero puede ejercer el cargo para ser considerado como independiente, separar los poderes entre presidente y consejero delegado o mantener la independencia de las comisiones de auditoría, nombramiento y retribuciones.

\subsubsection{Compensación de directivos}

Mención aparte merece esta cuestión de gobierno corporativo, por ser una de las más frecuentes dentro del activismo. Entre los aspectos que se negocian se encuentran: los criterios de evaluación del desempeño en las políticas de retribución, la aprobación de políticas retributivas específicas para consejeros ejecutivos y altos directivos, los límites para las indemnizaciones, la imposición de un límite en la retribución total anual del Consejo, la independencia de la Comisión de Retribuciones, el seguimiento de estándares internacionales de retribución y el aumento de la transparencia sobre retribuciones en el informe anual (Cuatrecasas y Georgeson, 2013).

Una de las cuestiones estrella en esta materia es el voto consultivo sobre el informe anual de remuneraciones (say on pay), concepto que hace referencia a consultar a accionistas sobre su opinión (say) sobre la retribución (pay) de los ejecutivos, a través de una votación (generalmente, no vinculante), al menos una vez cada tres años. Muchas empresas han adoptado internamente políticas de say on pay de modo voluntario durante la última década, si bien algunos países las han impuesto por ley (el Reino Unido en 2006 y Estados Unidos en 2011). En España, el voto consultivo de accionistas sobre el informe de retribuciones es obligatorio desde 2011 (Ley 2/2011 de Economía Sostenible).

Por lo general, estas votaciones, por su carácter consultivo, no tienen un impacto significativo en la remuneración. En cambio, se interpretan como «mociones de confianza» o "toque de atención», donde el acuerdo o desacuerdo con la remuneración representa la aprobación o no de la gestión y desempeño del equipo directivo.

\section{INTERNATIONAL BROTHERHOOD OF TEAMSTERS CONTRA MCKESSON}

International Brotherhood of Teamsters, sindicato de trabajadores en Estados Unidos y Canadá, lideró en 2017 una campaña por el no contra la empresa farmacéutica McKesson. A través de una campaña pública, en la que se sirvió de medios como la prensa, los piquetes y los comunicados escritos, movilizó (con éxito) a los inversores para que no aprobaran en la junta general el plan de compensación del CEO, John Hammergren, uno de los ejecutivos mejor pagados de EE.UU.

La acción sirvió para poner de manifiesto la oposición del sindicato, y de los accionistas, a la participación y lucro de McKesson con la "epidemia de opioides» (el término hace referencia al rápido aumento en el uso de opiáceos recetados y no recetados en Estados Unidos y Canadá desde 2010, sustancias asociadas a un elevado riesgo de adicción y sobredosis). Junto a la petición de voto contrario, el sindicato urgió al resto de accionistas a apoyar su propuesta de acuerdo para nombrar un presidente del Consejo independiente $y$, así, separar los dos cargos de CEO y presidente que en el momento ostentaba John Hammergren.

Aunque se trataba de una votación consultiva (sobre las retribuciones), la visibilidad mediática y el apoyo accionarial recibido por la campaña llevaron a que la compañia se reuniera con el sindicato y los accionistas para valorar sus posiciones y revisar el plan de retribución, y que se acordara la creación de un comité especial independiente de investigación.

\subsubsection{Cambios en la dirección o el consejo}

Dirigidos a sustituir al primer ejecutivo o a alguno de los miembros del órgano de administración cuyo desempeño en el cargo no ha sido el esperado. Para ello es muy frecuente emprender lo que se denominan "campañas por el no" (vote-no campaign), en las que los accionistas activistas tratan de movilizar al resto de accionistas para que voten en contra de la elección o reelección de los miembros del Consejo de Administración, del presidente del Consejo o del primer ejecutivo 
Las peticiones en materia de RSC buscan la introducción de mejores prácticas en asuntos sociales, ambientales y laborales.
Los accionistas disponen de varias opciones para reaccionar ante una gestión o un desempeño de la entidad con el que no están conformes: vender las acciones (exit), proponer y votar cambios (voice) o mantenerse (loyalty). de la compañia. Se trata de un gesto con el que los accionistas pueden mostrar su insatisfacción con la gestión que ha realizado el Consejo, que no lleva aparejado el nombramiento o voto a favor de otro candidato.

En este sentido, tienen un significado generalmente "simbólico" que busca dar visibilidad a las peticiones de los activistas en materia de gobierno o políticas corporativas, si bien en muchas ocasiones llegan a traducirse en cambios efectivos en la compañía e, incluso, en la sustitución del primer ejecutivo.

En el pasado, estas campañas se dirigian principalmente a obtener cambios en materia de gobierno corporativo, pero en los últimos años cada vez más fondos de cobertura e inversores las utilizan para lograr cambios en la estrategia o la gestión. Cuando la cúpula directiva se opone a cambiar determinados aspectos del gobierno corporativo o facilitar una fusión o adquisición, los accionistas activistas inician una campaña que toma la forma de proxy fight, en la que solicitan a otros accionistas que deleguen su poder de voto en ellos para lograr la mayoría en una votación. Generalmente, se dirigen a los accionistas meramente inversores y, en cuanto tales, no directamente interesados en la gestión social y en el control de la sociedad; su objetivo final es cambiar a los miembros del Consejo y nombrar otros más favorables a su posición. Los asesores de voto (proxy advisors) pueden tener un papel determinante en el resultado de la votación, por su capacidad de influir en el sentido del voto de los inversores institucionales.

\subsubsection{Cambios en RSC}

Busca la introducción de mejores prácticas en asuntos sociales, ambientales y laborales, incluyendo, por ejemplo, la mejora de los reportes de sostenibilidad, la introducción de políticas contra la discriminación, la mejora de prácticas en derechos humanos, la garantía de seguridad y salud de los productos, la aprobación y supervisión por el Consejo de la estrategia de sostenibilidad, la retribución y rendición de cuentas de la dirección por su desempeño en materia social y ambiental, la adopción de objetivos estratégicos en protección del medioambiente y el cambio climático, la gestión de la cadena de suministro, etc. Este tipo de peticiones de cambio suele proceder de los fondos de ISR, organizaciones de inspiración religiosa (faith-based investors) y fondos de pensiones públicos.

\section{ACTIVISMO ACCIONARIAL Y CAMBIO CLIMÁTICO}

La adopción del Acuerdo de Paris ha movilizado a muchos inversores socialmente responsables a favor de iniciativas a favor del cambio climático. Así, este se ha convertido en un tema recurrente entre las demandas de los accionistas hacia las compañias. Por ejemplo, la petrolera estadounidense ExxonMobil recibió en su junta de accionistas de 2017 un 62\% de votos a favor de presentar un informe sobre los impactos de cambio climático en el negocio a largo plazo. La misma propuesta también fue aprobada por mayoría en la junta de Occidental Petroleum, y presentada, pero no aprobada, en la de Chevron. Po su parte, varios fondos urgieron a Shell a publicar detalladamente cómo vincula el bonus de sus directivos a la reducción de emisiones de $\mathrm{CO}_{2}$.

A estas formas de activismo que se dirigen a introducir cambios en la empresa hay que añadir las solicitudes de información. Menos sobresalientes, pero mucho más frecuentes, engloban todas las cuestiones que los accionistas remiten a la compañia y con las que tratan de obtener más información, principalmente, sobre la estrategia y el desempeño financiero y, en menor medida, sobre el desempeño no financiero.

\subsection{INSTRUMENTOS}

Los accionistas disponen de varias opciones o instrumentos para reaccionar ante una gestión 0 un desempeño de la entidad con el que no están conformes, que se basan en el derecho a vender su acción libremente en el mercado, el derecho de voto o el derecho a la información que poseen como propietarios de acciones. Las posibles opciones suelen explicarse bajo el modelo exit, voice, and loyalty (salida, voz y lealtad) (Hirschman, 1970): vender las acciones (exit), proponer y votar cambios (voice) o mantenerse (loyalty). El activismo se enmarca en la segunda opción (voice) y ofrece un abanico de mecanismos para influir dentro de las decisiones que toma el Consejo, la 
dirección o la junta general, desde el envío de peticiones y el establecimiento de conversaciones privadas con los administradores y directivos hasta campañas públicas o mediáticas, pasando por la presentación y aprobación de propuestas ante la junta general o campañas de voto de oposición (Goodman et al. 2014), tal como veremos a continuación.

\subsubsection{Envío de comunicados}

Se trata de una forma bastante frecuente, accesible y sencilla de activismo, basada en el envío por correo electrónico o postal de comunicados escritos a los departamentos de relaciones con inversores u otros departamentos claves en el ámbito ESG, en los que se solicita más información o se realizan propuestas. En la mayoría de las ocasiones, estas propuestas se dirigen a reducir la remuneración de los ejecutivos, cuando se considera excesiva con relación al desempeño demostrado, o que el plan de compensación contiene condiciones ventajosas (por ejemplo, en cuanto a derechos de adquisición), o se basa en métricas inadecuadas (PwC, 2015). Se trata, por lo general, de acciones puntuales que no continúan en un proceso de diálogo a medio o largo plazo entre ambas partes (Spainsif, 2011) y relativamente "pasivas» (PwC, 2015). Son empleadas por todo tipo de accionistas, siendo la principal herramienta de los accionistas minoritarios cuando no acumulan el capital social suficiente para emprender otro tipo de acciones.

\subsubsection{Diálogo con administradores}

A través de reuniones presenciales, en general, con el órgano de administración o la alta dirección, los accionistas solicitan información, expresan sus posiciones y negocian las propuestas, con vistas a introducir nuevas políticas, prácticas, procedimientos o comportamientos en la entidad. Se trata de la técnica más empleada de participación empresarial y es considerada la más efectiva por los propios accionistas, particularmente, por los grandes inversores institucionales, quienes tienen más posibilidades de mantener este tipo de reuniones frente a los accionistas minoritarios (Spainsif, 2011). Así mismo, puede ser la técnica empleada por los fondos de inversión libre antes de adquirir una participación en el capital social de una compañia (Puente González, 2017). Las grandes empresas tienen a menudo oficinas de relación con el accionista dedicadas a este fin.

\subsubsection{Propuestas de acuerdo}

Los accionistas de cualquier sociedad cotizada pueden presentar una propuesta de acuerdo o incluir nuevos puntos en la orden de día ante la JGA, como elementos básicos para expresar su posicionamiento respecto a una temática y someterlo a votación ante el resto de accionistas. Las propuestas suelen buscar cambios dentro del gobierno o la gestión de la compañía (prácticas de gobierno corporativo, planes de compensación, supervisión de las funciones de auditoría o gestión de riegos), entre las que también se incluyen cambios en materia de RSC (por ejemplo, gasto en lobby, prácticas ambientales, prácticas laborales, relación con las comunidades locales, etc.) (PwC, 2015).

Figura 1. Tema o asunto sobre el que versan las propuestas de los accionistas (2016)

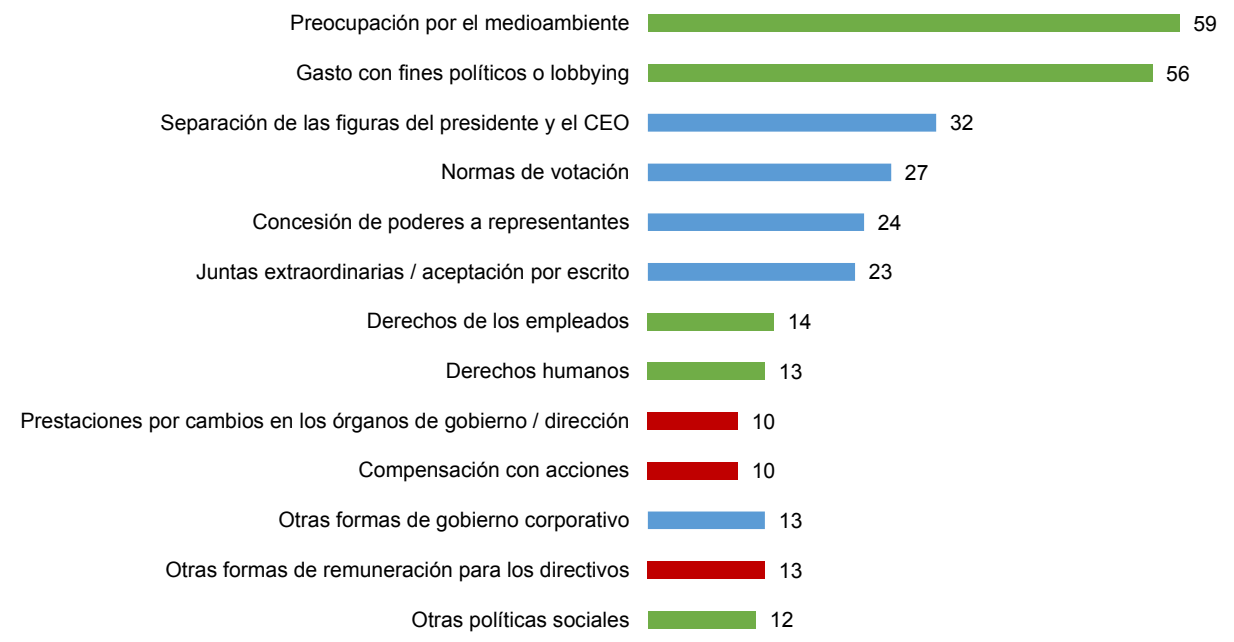

Fuente: Basado en The Manhatan Institute, An Annual Report on Corporate Governance and Shareholder Activism, ProxyMonitor.org. Fecha de último acceso: septiembre de 2017.
Las grandes empresas

tienen a menudo oficinas

de relación con el

accionista dedicadas a

facilitar el diálogo con

los administradores.

Las propuestas de acuerdo son un elemento básico para que los activistas expresen su posicionamiento respecto a una temática y lo sometan a votación ante el resto de accionistas. 
Las propuestas dan visibilidad a la postura del accionista e influyen en la marcha de la sociedad anónima, además de servir como elemento de negociación.
En España, este derecho está regulado por la Ley 31/2014, que permite a los accionistas que representen al menos el 3\% del capital social solicitar la introducción de nuevos puntos en el orden del día de la convocatoria de la junta general ordinaria y presentar propuestas de acuerdos sobre puntos del orden del día (art. 519).

Las propuestas son un mecanismo para, primero, dar visibilidad a la postura del accionista, al ponerla en conocimiento de los demás accionistas durante la junta general, y, segundo, influir en la marcha de la sociedad anónima, en caso de conseguir su aprobación. Los administradores de la compañía también tienen la opción de negociar con los accionistas activistas para prevenir que la propuesta de acuerdo llegue a ser presentada, con lo que una tercera finalidad de este mecanismo sería servir de "amenaza" y elemento de negociación en conversaciones privadas paralelas. Por otra parte, la aprobación de una propuesta de acuerdo por la mayoría del accionariado no obliga a los directores de la compañía a darle cumplimiento, si bien es cierto que no darle respuesta les expone a recibir una votación en contra al año siguiente.

\section{PROPUESTAS DE ACUERDO EN MATERIA ESG}

Muchas propuestas de acuerdo abordan temas de carácter social, medioambiental, político o laboral. Algunos de las peticiones más frecuentes en los últimos años han sido el cambio climático, la diversidad del Consejo, el gasto en lobby, los derechos humanos y el pago de impuestos; o se centran en prácticas concretas con impacto negativo como el fracking, la experimentación animal, el uso de energías contaminantes, los productos transgénicos, etc. Algunos casos representativos son:

- Repsol: accionistas particulares y fondos de inversión cedieron sus acciones para que Intermon Oxfam pudiese solicitar ante la JGA de 2009 mayor transparencia (publicación de gastos e ingresos país por pais) y garantías en el respeto a los pueblos indígenas.

- McDonald's: en 2013 recibió de sus accionistas una solicitud de análisis de los riesgos actuales y potenciales en materia de vulneración de derechos humanos en sus restaurantes, tanto en propiedad como en régimen de franquicia.

- Twitter: en 2017 vivió la campaña \#BuyTwitter, en la que el accionista minoritarito y activista Jim McRitchie propuso que la red social presentase un informe, preparado por consultores con experiencia en gobierno corporativo, sobre la viabilidad de vender la plataforma a sus usuarios de manera que adquiriese estructura de cooperativa.

\subsubsection{Votación}

Cada año, en la JGA, los accionistas tienen la oportunidad de votar sobre un gran número de cuestiones. Entre estas se encuentran las que la compañia propone a aprobación (las cuentas anuales individuales y consolidadas, el resultado de ejercicio, la gestión social, la actuación del Consejo de Administración, la actualización de sistema de gobierno corporativo, la renovación de Consejo de Administración, la política de remuneraciones de los consejeros, la distribución del dividendo, etc.) así como el resto de propuestas que otros accionistas logren incluir en el orden de día.

De esta manera, los accionistas pueden expresar su acuerdo o desacuerdo con la gestión de los administradores, así como respecto de introducir cambios en la estrategia, las operaciones, la política o el gobierno y, por consiguiente, de la marcha de la entidad. Así mismo, para aquellas propuestas que no son vinculantes, o que no logran la aprobación de la mayoría, la votación sigue siendo un excelente medio para dar visibilidad a la cuestión o trasladar la posición de los accionistas frente a la gestión de la empresa. Como ya vimos anteriormente, las vote-no campaigns, el say on pay o las proxy fights son situaciones de votación que se repiten con relativa frecuencia dentro del activismo accionarial y que permiten a sus participantes manifestar su oposición a la gestión realizada por la directiva o el Consejo e, incluso, lograr cambios en materia de administración o gobierno corporativo.

Los accionistas activistas tienen la opción de solicitar a otros accionistas que deleguen su poder de voto en ellos, de manera que puedan votar en su lugar. En España, la Ley de Sociedades de Capital entiende que ha habido solicitud pública de representación cuando una misma persona ostente la representación de más de tres accionistas (art. 186.3). Este recurso es empleado con relativa frecuencia por los hedge funds para unificar votos que les permitan hacerse con el control del Consejo durante las proxy fights; pero también otras entidades, como las asociaciones de accionistas o las $0 N G$, pueden ejercer esta solicitud pública de representación como vía para 
agrupar los intereses de los accionistas y reunir el capital social suficiente para presentar y obtener respaldo para una propuesta de acuerdo.

\subsubsection{Campañas públicas}

En esta modalidad, los accionistas se sirven de declaraciones públicas, el recurso a los medios de comunicación e, incluso, del enfrentamiento en público, para dar visibilidad a su petición ante la sociedad, ejercer presión sobre la compañía y lograr así su aprobación. Se trata de una práctica poco frecuente, ya que una movilización de este tipo puede desprestigiar a la compañia y, como consecuencia, repercutir negativamente sobre el valor de sus acciones en bolsa. Por este motivo, es una técnica empleada generalmente por accionistas minoritarios, en muchas ocasiones $0 N G$, como manera de ejercer presión tras presentar una propuesta de acuerdo, pues al poseer un porcentaje pequeño de las acciones, no se ven tan afectadas por una eventual devaluación (Goodman et al. 2014). De manera más simple, el hecho de plantear preguntas en las JGA puede ser un mecanismo eficiente para dar visibilidad a una cuestión determinada.

Una alternativa a este recurso es la realización de campañas que movilicen a los accionistas por canales privados, sin que la cuestión llegue a ser de conocimiento de la opinión pública. Para ello, los activistas cuentan con mecanismos como el envío de comunicados o las conversaciones directas con otros accionistas, el planteamiento de las cuestiones sociales objeto de preocupación en las reuniones celebradas entre inversores institucionales y comités de gestión e, incluso, la convocatoria de juntas extraordinarias para discutir dichas cuestiones (Eurosif, 2005).

\section{ACTIVISMO MEDIÁTICO EN LA JUNTA GENERAL}

Las JGA, por el número de accionistas que congregan y por su puntualidad, son, para muchos activistas, la ocasión para presentar sus reivindicaciones. Lo más frecuente son las propuestas de acuerdo, que implican que la petición se dé a conocer a todos los accionistas, y que, al ser publicadas en el orden del día, sean de dominio público, por lo que los medios de comunicación pueden hacerse eco tanto la petición como del resultado de la votación.

Además, los accionistas más activistas, relacionados con el mundo de las ONG y los sindicatos, aprovechan esta ocasión para reivindicarse a las puertas del encuentro bajo la forma de piquetes, manifestaciones, protestas, actuaciones simbólicas, etc. que también reciben cobertura mediática. Por ejemplo:

- Activistas de diversas organizaciones ambientalistas locales se personaron en la JGA de Duke Energy, en Charlotte (Carolina del Norte, EE. UU.), para solicitar al CEO que levantase el bloqueo de la venta de energía solar.

- Una delegación de Amazon Watch protestó en la junta general de Chevron por la actividad contaminante de la compañía en Ecuador.

- El sindicato Fight for 15 congrega cada año a cientos de trabajadores de McDonalds para solicitar ante la JGA el aumento del salario mínimo (a 15 dólares la hora).

- Amnistía Internacional accedió a la junta de accionistas de Ferrovial para solicitar ante la dirección de la empresa el fin, cuanto antes, de las operaciones de gestión de los centros de "tramitación» de personas refugiadas en las islas de Nauru (Micronesia) y Manus (Papúa Nueva Guinea).

- Activistas de la Campaña Banca Armada intervienen anualmente en la JGA del Banco Santander, BBVA, CaixaBank y Banco Sabadell para denunciar la financiación que estas entidades bancarias prestan a las principales empresas españolas de armas. En más de una ocasión, esta intervención se ha visto acompañada por protestas simbólicas de la mano de otros activistas en las que se arrojaron pintura roja para simbolizar la "sangre, el dolor y el sufrimiento" que generan los negocios del banco.

Para concluir, cabe señalar cómo los objetivos y estrategias que siguen los activistas están interrelacionados. La consecución (o no) de unos conduce al empleo de los otros. Los accionistas pueden utilizar algunas peticiones para luego conseguir otras (por ejemplo, cambios en el equipo directivo para lograr cambios en la estrategia) o comenzar las campañas con tácticas discretas para luego pasar a otras más ofensivas (por ejemplo, pasar del envío de comunicados a presentar una propuesta que, en última instancia, ejerza la presión suficiente para mantener reuniones privadas con el equipo directivo). Por lo general, se trata de un proceso de escalado, que los accionistas comenzarian trasladando las preocupaciones al equipo directivo y consejeros, para luego hacerlo público y trasladarlo a otros accionistas, a continuación, presentar una propuesta de acuerdo y participar en la junta general; en última instancia, proponer nuevos candidatos

\author{
Los objetivos y \\ estrategias que siguen \\ los activistas están \\ interrelacionados. La \\ consecución (o no) de \\ unos conduce al empleo \\ de los otros.
}


La empresa puede considerar el diálogo con accionistas como parte de su RSC y de su diálogo con los grupos de interés.

\author{
Un diálogo exitoso \\ requiere realizar una \\ comunicación continua \\ con los accionistas \\ estratégicos, pero \\ también escuchar y dar \\ respuesta a las demandas \\ externas.
}

a elección al Consejo o recurrir a mecanismos expeditivos como los litigios o el arbitrio; y ya, finalmente y como último recurso, optar por la desinversión de la compañía (o amenazar con la misma) (ICGN, 2016).

\section{RECOMENDACIONES PARA EL DIÁLOGO CON ACCIONISTAS}

El diálogo con accionistas se presenta como un mecanismo muy recomendable para sacar el mayor potencial de las campañas de activismo y minimizar el riesgo de una campaña hostil.

El diálogo permite alinear los intereses de la compañia y de los accionistas. Sirve tanto para recoger las solicitudes de los accionistas - para tenerlas en cuenta a la hora de tomar las decisiones-, como para explicar a estos las razones por las que la compañia ha decidido tomar un rumbo determinado. Por ello, un diálogo exitoso requiere realizar una comunicación continua con los accionistas estratégicos, pero también escuchar y dar respuesta a las demandas externas. Los inversores también agradecen que la empresa, además de ser reactiva, se dirija a ellos de manera proactiva y cree el ambiente propicio para el diálogo, el debate y la propuesta de iniciativas.

La empresa puede considerar el diálogo con accionistas como parte de su RSC y de su diálogo con los grupos de interés. Además de prevenir o solucionar una campaña de activismo, el diálogo resulta beneficioso para la compañía en numerosos aspectos como introducir nuevas prácticas y políticas que justifican el desempeño de la compañía y la lealtad de los accionistas, favorecer el entendimiento con las agencias de calificación no financiera y los gestores de ISR o fortalecer la reputación de la empresa basándose en la transparencia y la efectividad del diálogo (Forética, 2009). Algunas recomendaciones para llevar a cabo este diálogo son (IRRCl, 2011; Llorente y Cuenca, 2013; Goranova y Verstegen, 2014; PwC, 2015).

\subsection{ANTICIPARSE}

- Ponerse en el lugar del accionista e identificar aquellos aspectos que podrían llevarle a presentar una propuesta. La compañía puede guiarse para ello a través de noticias y estudios sobre cuáles son las cuestiones más relevantes entre el accionariado. También será de gran utilidad el análisis de riesgos corporativo, con el que adelantar las posibles dudas y críticas de los accionistas con relación a la estrategia y el desempeño, y preparar las respuestas.

- Informar por adelantado. Dado que en muchas ocasiones el principal interés de los activistas es obtener información, tanto sobre la estrategia como sobre el desempeño financiero y el no financiero, la compañía puede proporcionar a los accionistas estos datos antes de que los soliciten. De especial importancia es que esta información sea relevante y periódica, rebasando la puntualidad del informe anual para la junta general. También es importante saber comunicar el plan estratégico, poniendo énfasis en explicar cómo se creará el valor, para mantener el alineamiento con los accionistas.

- Hacer seguimiento de las demandas que los activistas están dirigiendo hacia otras entidades (particularmente las del sector) e implementar estas prácticas a nivel corporativo antes de que los accionistas lo soliciten.

\subsection{PLANIFICAR}

- Conocer los diferentes tipos de accionistas y priorizarlos según su importancia estratégica. Aspectos como la composición accionarial, el objetivo de la inversión, los criterios de decisión, la capacidad de influencia, el alineamiento con los valores corporativos o el grado de organización de los accionistas influyen en el tipo de demandas y la intensidad de las campañas.

- Contar con un plan de relaciones basado en este conocimiento de la composición accionarial, a partir del cual asignar los interlocutores, la forma y la frecuencia de las interacciones, y los mecanismos de diálogo más apropiados para cada tipo de accionista. 
- Definir claramente los mensajes claves que se quieren comunicar y preparar un equity story atractivo (pero ajustado a la realidad de la compañía).

- Preparar a los interlocutores de la entidad para el diálogo, explicándoles la manera de atender a cada tipo de accionistas, aportándoles argumentos y contrargumentos para responder a sus cuestiones y creando un discurso unificado para todos ellos. Es recomendable que dicho discurso se apoye en datos reales acerca del desempeño de la compañía y en cómo esta está cumpliendo con los objetivos de creación de valor a largo plazo.

\subsection{MANTENER RELACIONES CONTINUADAS}

- Facilitar espacios de diálogo; en concreto, los encuentros directos con el Consejo de Administración y el equipo directivo, pues es con quienes los inversores tienen mayor interés en involucrarse. Otros servicios y herramientas de información (newsletters para accionistas, guías de ayuda a los accionistas, dirección de contacto permanente, divulgación periódica de información corporativa, noticias, estudios temáticos o mensajes de la dirección, oferta exclusiva de servicios como conciertos, exposiciones, conferencias, etc.) pueden contribuir sensiblemente a mejorar las relaciones con este colectivo, que pasa a recibir atención e información de manera continua.

- Acercarse proactivamente a los inversores y solicitar su asesoramiento o su aprobación ante determinadas cuestiones.

- Tratar los asuntos que sean de verdadero interés para el accionista.

\subsection{DAR RESPUESTA}

- Mostrar la apertura y la predisposición de la compañía a escuchar nuevas ideas, a entablar un diálogo constructivo y a alcanzar acuerdos.

- Buscar áreas de consenso. Aunque, en determinadas ocasiones, se tenga que recurrir a reacciones más defensivas (por ejemplo, litigios), puede ser más conveniente evitar el enfrentamiento directo con los activistas. En general, este colectivo, al igual que la compañia, prefiere alcanzar un acuerdo lo antes posible y evitar que la campaña se prolongue. Las áreas de consenso facilitarán las negociaciones y la firma de acuerdos.

- Responder con acciones concretas. Para los accionistas, el objetivo del diálogo no es conversar con la compañía, sino implementar nuevas prácticas o transformaciones a nivel corporativo. Por ello, es recomendable que los resultados del diálogo no se limiten a meros compromisos, sino que se materialicen en cambios tangibles.

- Justificar tanto a los activistas como al resto de accionistas y grupos de interés los motivos de la aceptación o el rechazo de la propuesta y cómo esta decisión redundará en su beneficio a largo plazo. Esto les ayudará a saber que se les tiene en cuenta y a comprender la manera en que la compañía toma decisiones, y fortalecerá la confianza en la actuación de los altos ejecutivos.

- Cumplir con lo acordado. Algunas compañías introducen el discurso del desarrollo sostenible para evitar la presión de los accionistas sin realizar modificaciones significativas en los procesos o en la organización. Es importante que, si se aprueba la propuesta de un accionista, esta se lleve a término.

\subsection{REALIZAR UN SEGUIMIENTO}

- Emplear indicadores y herramientas para medir y evaluar el plan de relaciones y sus resultados. El número de encuentros mantenidos, la cifra de propuestas presentadas 0 retiradas, y el signo favorable o negativo de los votos, así como el número de cambios y nuevas políticas introducidos, pueden ser algunos de los criterios para evaluar los resultados del diálogo, al igual que otros indicadores de tipo cualitativo que tengan en cuenta, por ejemplo, el aumento o la disminución del compromiso de los accionistas, el peso estratégico del inversor, la predisposición o la hostilidad previas de los activistas, así como el alcance y la envergadura de los acuerdos alcanzados.
El plan de relaciones permite asignar los interlocutores, la forma y la frecuencia de las interacciones, y los mecanismos de diálogo más apropiados para cada tipo de accionista.

Los accionistas, al

igual que la compañía, prefieren alcanzar un acuerdo lo antes posible y evitar que la campaña se prolongue. Buscar áreas de consenso facilita las negociaciones y la firma de acuerdos. 
Para garantizar que

la comunicación

sea bidireccional, es

recomendable habilitar

espacios para que

los accionistas y los

inversores puedan dar su opinión.

\section{Resulta fundamental \\ comprometerse con \\ el diálogo continuo \\ y no recurrir a este \\ únicamente en \\ situaciones de crisis.}

La principal aportación

del activismo accionarial

ha sido la mejora de las

prácticas de gobierno

corporativo.
En materia concreta de RSC, se pueden mantener reuniones informativas (roadshows) para dar a conocer la estrategia sostenible de la compañía entre los accionistas, los fondos ISR, las agencias de calificación y los expertos. Asimismo, también es conveniente aumentar la divulgación de información y fomentar el diálogo mediante encuentros directos con estos colectivos, la participación en paneles y en conferencias, y la distribución de publicaciones y documentos (Forética, 2009). Para garantizar que la comunicación sea bidireccional, es recomendable habilitar espacios para que los accionistas y los inversores puedan dar su opinión, así como aprovechar estos encuentros para preguntarles directamente por ella o realizar cuestionarios sobre RSC.

En muchos casos, es posible que los accionistas no estén interesados en temas de sostenibilidad o no posean conocimientos acerca de ellos. Por eso, la compañia tendrá que realizar un especial esfuerzo pedagógico para explicar la información no financiera y los resultados en ratings, y sensibilizar sobre la importancia de los asuntos de ESG, hasta que los accionistas los interioricen.

También es previsible que el diálogo sea más torpe al principio, aunque su fluidez será cada vez mayor a medida que la compañia gane experiencia y cimienten las relaciones (PwC, 2015). Por ello, resulta fundamental comprometerse con el diálogo continuo y no recurrir a este únicamente en situaciones de crisis. Una relación sólida y constante con los accionistas es más segura y eficaz a la hora de conseguir los objetivos propuestos y permite explicar de manera más eficiente la realidad de la compañía, así como dar razones coherentes ante los argumentos en contra (Llorente y Cuenca, 2013).

\section{INFLUENCIA DEL ACTIVISMO ACCIONARIAL EN LA RESPONSABILIDAD SOCIAL CORPORATIVA}

Un aspecto que ha acaparado la atención tanto de los accionistas como de los empresarios, así como de los expertos en sostenibilidad o de los investigadores, son los efectos del activismo accionarial en el desempeño de la compañía y, en el caso que nos ocupa, su capacidad fáctica para impulsar prácticas más responsables en ella. Tal como ya señalamos, existen dos tendencias divergentes: la que apuesta por el incremento de los beneficios económicos a corto plazo y la que demanda la introducción de prácticas sociales más responsables y sostenibles a largo plazo (Uysal y Tsetsura, 2015). Si bien lo cierto es que la primera de ellas es la predominante, esto no impide que el movimiento accionarial pueda verse como un impulsor significativo de la responsabilidad.

La principal aportación en esta materia ha sido la mejora de las prácticas de gobierno corporativo, que ha llegado a constituir un punto fundamental en los temas relativos a la política de retribuciones, la continuidad del CEO o los derechos de los accionistas (blindajes en los contratos, píldoras envenenadas, desclasificación de los consejos de administración, etc.) (Goranova y Verstegen, 2014). Esta mejora también ha contribuido al empuje de prácticas con las que la compañía pretende mejorar su impacto en la sociedad, como pueden ser la introducción de códigos éticos o el incremento del reporting no financiero ( $y$, particularmente, la participación en iniciativas como Carbon Disclosure Project o Global Reporting Initiative), si bien es cierto que este efecto es más pronunciado cuando el sector en el que opera la compañia también está sensibilizado o cuando existe una amenaza de regulación (Goranova y Verstegen, 2014). Desde el punto de vista de la teoría de los stakeholders, estas prácticas propias de la RSC y el buen gobierno repercuten en último término en la mejora del desempeño económico de la empresa, si bien también hay autores que señalan que el coste de asumir y dar respuesta a la campaña podría tener un impacto negativo en la cuenta de resultados de muchas empresas (Sjöström, 2008).

En esta misma línea, y en lo que respecta a la variación del valor en bolsa de la compañía como resultado del activismo accionarial, los resultados no son concluyentes. Las investigaciones arrojan resultados dispares, ya que señalan que la recepción de propuestas de mejora en materia de ESG afecta al valor de forma positiva, dado que genera la expectativa de que se introducirán nuevas prácticas, pero también negativamente, dado que constituye una señal de que la compañia todavía no dispone de ellas (Uysal y Tsetsura, 2015). La validez de estos resultados se vería distorsionada por el hecho de que las campañas se desarrollen en muchas ocasiones en el ámbito privado, así como por que las propuestas no sean vinculantes y, por consiguiente, no exista la garantía de que vayan a ser implementadas por los directivos (Goranova y Verstegen, 2014). 
Más allá del valor monetario, sí que parece haber un beneficio para la compañía en términos de mantenimiento de su legitimidad e incremento de su reputación, al transmitir a través de su comportamiento y su comunicación que las acciones que implementa están orientadas al beneficio de sus grupos de interés (Uysal y Tsetsura, 2015).

Tal como puede verse, es difícil medir la efectividad de las campañas de los accionistas y su capacidad para influir en la empresa. La realidad es que los activistas pueden llegar a presentar la propuesta, pero, en la mayor parte de los casos, esta no obtiene el voto favorable mayoritario en la JGA. También puede suceder que, aunque se apruebe, los directivos y los consejeros implementen únicamente los puntos más simbólicos de la propuesta y se olviden de otros que hubieran supuesto cambios significativos para la organización (Sjöström, 2008).

En todo caso, más allá de los resultados concretos que cada campaña de activismo tenga en cada compañia, el impacto más destacable de este movimiento a nivel global habría sido el empoderamiento de los accionistas como colectivo capaz de impulsar cambios a nivel corporativo. Así, los accionistas han demostrado en las últimas décadas tener poder real para proponer y hacer avanzar mejoras entre las compañías, al mismo tiempo que los directivos y los consejeros, a la luz de este crecimiento social, y tras evidenciar sus resultados, se han hecho más sensibles a sus peticiones y han incrementado su predisposición a dialogar y a implementar estas nuevas prácticas. Con ello, el activismo habria contribuido a generar un clima más propicio para el avance de la RSC, al haber aumentado la visibilidad de los temas ESG entre otros accionistas, los administradores y los directivos, e, incluso, haber abierto el debate a una audiencia mayor (0'Rourke, 2003). Además, también habría propiciado la mejora de las prácticas a nivel sectorial, gracias a todas aquellas empresas que prefieren introducirlas de manera anticipada para evitar una campaña de este tipo o una pérdida de competitividad frente a las compañias que ya las hubieran introducido.

Figura 2. Resultados de las campañas activistas

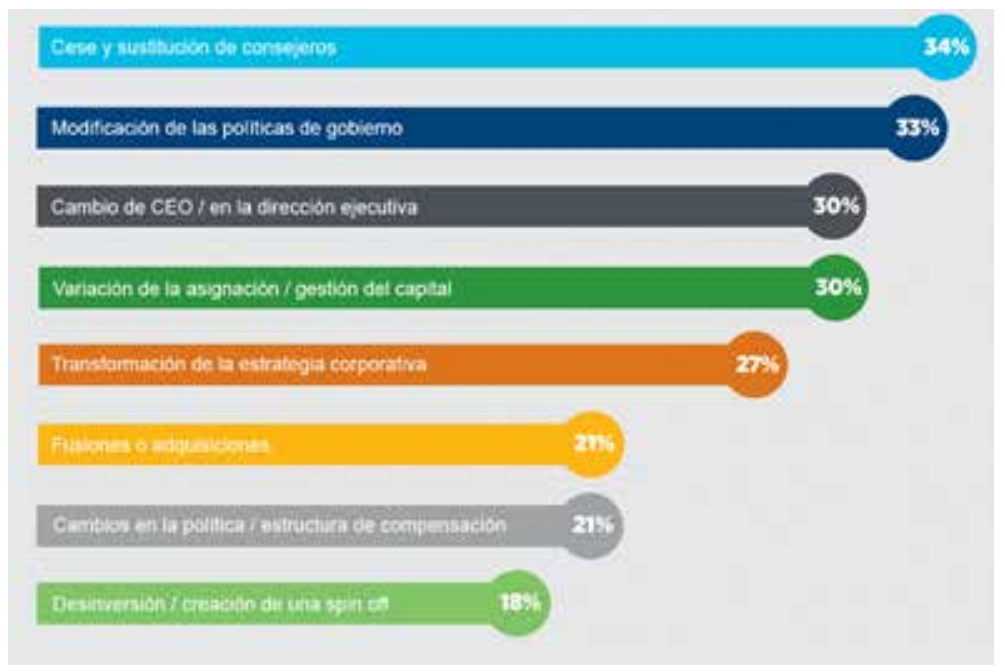

Fuente: Basado en NYSE Governance Services, Evercore y Spencer Stuart (2016), The effect of shareholder activism on corporate strategy. Fecha de último acceso: septiembre de 2017

En conjunto, el activismo accionarial actúa como un mecanismo de supervisión capaz de mejorar la eficiencia del gobierno corporativo y de tener un impacto positivo en el valor, el desempeño y la toma de decisiones de la empresa.

\section{El activismo accionarial} ha tenido un impacto destacable a nivel global en el empoderamiento de los accionistas como colectivo capaz de impulsar cambios a nivel corporativo.

\section{El activismo ha contribuido a generar un clima más propicio para el avance de la RSC, al aumentar la visibilidad de los temas ESG entre otros accionistas, los administradores y los directivos, e incluso, abrir el debate a una audiencia mayor.}




\section{CONCLUSIONES: RESPONSABILIDAD SOCIAL CORPORATIVA Y CREACIÓN DE VALOR}

La divergencia entre el activismo accionarial social y el financiero es el reflejo de un debate ya clásico sobre si la responsabilidad de la empresa es maximizar el valor para los accionistas o si, por el contrario, debe buscar el beneficio de todos los grupos de interés.

\footnotetext{
La implicación efectiva y sostenible de los accionistas, a través del activismo más social, se postula como una de las piedras angulares del modelo de gobierno corporativo y de RSC de las sociedades cotizadas.
}

A lo largo de este Cuaderno, hemos mencionado en varias ocasiones cómo dentro del activismo accionarial coexisten dos corrientes divergentes: la primera, el activismo financiero, que se dirige hacia la maximización del valor para el accionista a corto plazo a través de la rentabilidad financiera; la segunda, el activismo social, que se orienta al valor a largo plazo a través de la sostenibilidad. Esta divergencia es el reflejo de un debate ya clásico dentro de la ética empresarial, que gira en torno a si la responsabilidad de la empresa es maximizar el valor para los accionistas o si, por el contrario, debe buscar el beneficio de todos los grupos de interés.

No es objeto de este Cuaderno entrar a examinar uno u otro modelo ni responder a la cuestión de cuál debe ser el modelo de creación de valor de la empresa, y mucho menos entrar a evaluar qué se entiende por "valor». Lo que sí que cabe señalar es que, tanto en una como en otra postura, tiene cabida la creación de valor económico para el accionista, que se persigue a través de la actividad de la compañia y que es algo legítimo: al fin y al cabo, el objetivo de cualquier compañia es la obtención de un beneficio económico. De la misma manera, para el accionista, el beneficio económico es un incentivo que le lleva a aceptar los riesgos que conlleva participar en la organización a través de su capital inversor. La diferencia entre ambas corrientes radicaría, por tanto, en la manera en que se crea este valor para el accionista y hasta qué punto es legítimo primar los intereses de los accionistas por delante de los de los otros grupos de interés.

Los resultados de la actividad de las empresas exceden lo estrictamente económico financiero y se adentran en el ámbito de lo social (Sánchez-Calero Guilarte, 2006); de ahí que, desde el punto de vista de la ética deontológica $-\mathrm{y}$ de la RSC-, la creación de beneficio económico no se puede realizar a cualquier coste: el medioambiente, el bienestar de los empleados, la calidad de los productos o servicios, etc. La maximización del valor de la empresa a favor del accionista no puede significar que los intereses de los accionistas sean el objetivo exclusivo de los administradores ni que persigan dicha meta a cualquier precio, ignorando los intereses vinculados de los otros grupos implicados en la marcha de la sociedad o a la propia comunidad en la que dicha sociedad se ubica (Comisión Olivencia, 1998).

Es aquí donde entra en juego la RSC, entendida como una gestión responsable de los negocios que crea valor para todos los grupos de interés -donde, por supuesto, se incluye el valor económico para los accionistas-. Una integración estratégica de la RSC en la empresa no tiene por qué ir en detrimento de la rentabilidad o la competitividad, sino, más bien, al contrario: es razonable pensar que, en una sociedad en la que las empresas (junto con los ciudadanos y las demás instituciones) se comportan de manera responsable, se propicia un entorno favorable para el desarrollo de la actividad mercantil y comercial (por ejemplo, al no existir corrupción, asimetrias de información, violencia, desigualdad, etc.) en condiciones de mayor eficiencia (sin generar externalidades negativas que, al fin y al cabo, pueden interferir en la vida de la empresa y de los miembros que la componen).

La implicación efectiva y sostenible de los accionistas, a través del activismo más social, se postula así como una de las piedras angulares del modelo de gobierno corporativo y de RSC de las sociedades cotizadas. El activismo fortalece el sistema de control y equilibrio, y constituye un instrumento efectivo para contribuir a mejorar el rendimiento financiero y no financiero de dichas sociedades, siempre que se mantenga la perspectiva de creación de valor para las distintas partes interesadas. 


\section{BIBLIOGRAFÍA}

ACTIVIST INSIGHT (2017), Activist investing: An annual review of trends in shareholder activism. Disponible en: https://www.activistinsight.com/wp-content/uploads/2017/02/ TheActivistlnvestingAnnualReview2017AIM.pdf?×83756. Fecha de último acceso: septiembre de 2017.

ARGANDOÑA, A. (2007), "Responsabilidad social y creación de valor para el accionista: ¿objetivos contrapuestos o complementarios?», Cátedra "Ia Caixa" de Responsabilidad Social de la Empresa y Gobierno Corporativo, OP 7/16.

CMS (2016), Shareholder Activism: A European Perspective. Disponible en: https://cms.law/ en/INT/Publication/Shareholder-Activism-A-European-Perspective. Fecha de último acceso: septiembre de 2017.

COMISIÓN ESPECIAL PARA EL ESTUDIO DE UN CÓDIGO ÉTICO DE LOS CONSEJOS DE ADMINISTRACIÓN DE LAS SOCIEDADES (Comisión Olivencia) (1998), El gobierno de las sociedades cotizadas. Disponible en: https://www.cnmv.es/DocPortal/Publicaciones/CodigoGov/govsocot. pdf. Fecha de último acceso: septiembre de 2017.

CREDIT SUISSE (2016), «The activism agenda: What are activist investors looking for?», Corporate Insights, 3.er trimestre. Disponible en: https://www.credit-suisse.com/media/assets/microsite/ docs/corporate-insights/credit-suisse-corporate-insights-q3-2016.pdf. Fecha de último acceso: septiembre de 2017.

CUATRECASAS Y GEORGESON (2013), El gobierno corporativo y los inversores institucionales. Disponible en: http://www.cuatrecasas.com/media_repository/docs/esp/el_gobierno_ corporativo_2013_956.pdf. Fecha de último acceso: septiembre de 2017.

EUROSIF (2005), Pension Programme SRI Toolkit 2004-2005. Disponible en: https://www.eurosif. org/pension-fund-toolkit-2004-2005/. Fecha de último acceso: septiembre de 2017.

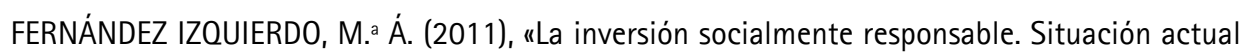
en España", Observatorio de Divulgación Financiera, Nota técnica 11. Disponible en: http://www. iefweb.org/es/finanzas/visordocumentospdf/25. Fecha de último acceso: septiembre de 2017.

FORÉTICA (2009), Diálogo con los grupos de interés: Guía práctica para empresas y stakeholders. Disponible en: http://www.foretica.org/wp-content/uploads/2016/01/cuaderno_foretica_14_ dialogo_grupos_interes.pdf. Fecha de último acceso: septiembre de 2017.

GLAC, K. (2014), "The Influence of Shareholders on Corporate Social Responsibility", Economics Management, and Financial Markets, 9(3), pp. 34-72.

GLOBAL SUSTAINABLE INVESTMENT ALLIANCE (2017), The 2016 Global Sustainable Investment Review. Disponible en: http://www.gsi-alliance.org/wp-content/uploads/2017/03/GSIR _ Review2016.F.pdf. Fecha de último acceso: septiembre de 2017.

GOODMAN, J, C. LOUCHE, K. VAN CRANENBURGH, y D. ARENAS (2014), "Social shareholder engagement: The dynamics of voice and exit», Journal of Business Ethics, 125(2), pp. 193-210.

GORANOVA, M., y L. VERSTEGEN (2014), "Shareholder Activism: A Multidisciplinary Review», Journal of Management, 40(5), pp. 1230-1268.

HIRSCHMAN, A. O. (1970), Exit, Voice, and Loyalty: Responses to Decline in Firms, Organizations, and States, Harvard University Press.

INTERNATIONAL CORPORATE GOVERNANCE NETWORK (ICGN) (2016), The ICGN Global Stewardship Principles. Disponible en: http://icgn.flpbks.com/icgn-global-stewardshipprinciples/\#p=1. Fecha de último acceso: septiembre de 2017.

INVESTOR RESPONSIBILITY RESEARCH CENTER INSTITUTE (IRRCI) (2011), The State of Engagement between U.S. Corporations and Shareholders. Disponible en: https://irrcinstitute.org/wp-content/ uploads/2015/09/IRRC-ISS_EngagementStudy1.pdf. Fecha de último acceso: septiembre 2017. 
JEFATURA DE ESTADO (2014), Ley 31/2014, de 3 de diciembre, por la que se modifica la Ley de Sociedades de Capital para la mejora del gobierno corporativo, BOE núm. 293, de 4 de diciembre, pp. 99793 - 99826.

LLORENTE Y CUENCA (2013), Activismo societario: del problema a la oportunidad. Disponible en: http://www.desarrollando-ideas.com/publico/130531_dmasi_Articulo_activismo_societario. pdf. Fecha de último acceso: septiembre de 2017.

MINISTERIO DE ECONOMÍA Y HACIENDA (2007), Real Decreto 1362/2007, de 19 de octubre, por el que se desarrolla la Ley 24/1988, de 28 de julio, del Mercado de Valores, en relación con los requisitos de transparencia relativos a la información sobre los emisores cuyos valores estén admitidos a negociación en un mercado secundario oficial o en otro mercado regulado de la Unión Europea. BOE núm. 252, de 20 de octubre, pp. 42692-42708.

O'ROURKE, A. (2003), "A new politics of engagement: shareholder activism for corporate social responsibility", Business Strategy and the Environment, 12(4), pp. 227-239.

PARLAMENTO EUROPEO Y EL CONSEJO DE LA UNIÓN EUROPEA (2017), Directiva (UE) 2017/828 del Parlamento Europeo y del Consejo de 17 de mayo de 2017 por la que se modifica la Directiva 2007/36/CE en lo que respecta al fomento de la implicación a largo plazo de los accionistas. Diario Oficial de la Unión Europea, de 20 de mayo (L 132).

PUENTE GONZÁLEZ, I. A. (2017), "La influencia del activismo accionarial en el gobierno corporativo de las sociedades de capital. Régimen jurídico comparado: España, Reino Unido y Estados Unidos». Trabajo fin de máster, Colegio Universitario de Estudios Financieros (CUNEF).

PwC (2013), Proxy Advisors: ¿Qué impacto tienen en las sociedades cotizadas españolas? Disponible en: https://www.PwC.es/es/publicaciones/gestion-empresarial/assets/proxy-advisors. pdf. Fecha de último acceso: septiembre de 2017.

PwC (2015), Shareholder activism: who, what, when, and how? Disponible en: https://www.PwC. com/us/en/governance-insights-center/publications/assets/PwC-shareholder-activism-fullreport.pdf. Fecha de último acceso: septiembre de 2017.

SÁNCHEZ-CALERO GUILARTE, J. (2006), "Creación de valor, interés social y responsabilidad social corporativa», Derecho de sociedades anónimas cotizadas, Editorial Aranzadi, pp. 851-913.

SJÖSTRÖM, E. (2008), "Shareholder activism for corporate social responsibility: what do we know?», Sustainable Development, 16(3), pp. 141-154.

SPAINSIF (2011), Diálogo activo accionarial en España. Disponible en: http://www.observatoriorse.org.es/Publicaciones/spainsif_informe_2011_w3.pdf. Fecha de último acceso: septiembre de 2017.

UYSAL, N., y K. TSETSURA (2015), "Corporate governance on stakeholder issues: shareholder activism as a guiding force", Journal of Public Affairs, 15(2), pp. 210-219.

WORLD RESOURCE INSTITUTE (WRI) (2016), Navigating the Sustainable Investment Landscape. Disponible en: http://www.wri.org/sites/default/files/Navigating_the_Sustainable_Investment_ Landscape_0.pdf. Fecha de último acceso: septiembre de 2017. 

de Responsabilidad Tel.: 932534200 Social Corporativa 